\title{
Simulation and Experimental Research on the Influence of Tool Geometries on the Cutting Force of High Temperature Alloy
}

\author{
Fengyun $\mathrm{Yu}^{1, \mathrm{a}^{*}}$, He Wang ${ }^{1, \mathrm{~b}}$ and Yunliang $\mathrm{Fu}^{1, \mathrm{c}}$ \\ ${ }^{1}$ Heilongjiang University of Science and Technology, Harbin, 150022, China \\ a1578415766@qq.com, ${ }^{b} 346786233 @ q q . c o m,{ }^{c} 772370969 @ q q . c o m$
}

\begin{abstract}
For the difficult-to-process characteristics of the aero-engine turbine disk plank produced by Nickel-based superalloy GH4169 that appeared in the turning process, the numerical simulation and experimental research were conducted in this paper. The twodimensional orthogonal cutting model of the Nickel-based superalloy GH4169 was established to conduct the single factor experiment, in which the rake angle and tip radius were as the single variable, and the influence of cutting force caused by the rake angle and tip radius was researched by the finite element analysis software ABAQUS. The correctness of the simulation modal was verified by the comparison of the cutting force data obtained in simulation and the experimental result. The study demonstrates the fact that the back force $F_{y}$ will decrease while the feed force $F_{f}$ and the main cutting force $F_{c}$ will increase slowly with the increase of the rake angle. The back force $F_{y}$ will increase with the increase of the tip radius. In addition, the changing trend of cutting force obtained in the experiment was consistent with that of simulation. Under the experimental conditions, the rake angle of $10^{\circ}$ and tip radius $0.4 \mathrm{~mm}$ were suitable processing parameters for machining the Nickel-based superalloy GH4169.
\end{abstract}

Keywords: the rake angle; tip radius; cutting force; simulation; experiment

\section{Introduction}

The high-temperature alloy, for its well high temperature plastic, high temperature oxidation resistance and mechanical properties at room temperature and high temperature, has been widely used in the area of aerospace. It is one of typical difficult machining materials. In the process of machining the material, there always been some phenomenon such as, increased cutting force, cutting temperature, and easily hardening. With the combination of computer technology and mechanical disciplines, the appearance of many special simulation software easily applied to computers, lots of technical problems, which are difficult to solve in the engineering area, could be solved with computer numerical simulation. ABAQUS, based on the theory of finite elements analysis, is an engineering analysis software, by which the metal cutting process could be researched well [1]. When study the mechanism of machining metal, the cutting force is one of important research objects. In the process of cutting metal, the tool wear and surface quality of machined tools were influenced by cutting force, and meanwhile, the source of cutting heart and the cutting force have a direct connection. So, it is important for to optimized tool material and improve the surface quality of the machined metal to study the changing trend for cutting force appeared in the process of machining metal.

The in-depth research for the problems, such as establishment of finite element model and the material constitutive relation of Titanium Ti6Al4V [2], two-dimensional and three-dimensional numerical simulation in the high speed cutting process of nickel-based

*Corresponding Author 
superalloy GH4169 [3-4], the cutting force influenced by cutting parameters when cutting the high temperature alloy GH4169 with the ceramic tools [5-6] and so on, was conducted by domestic and foreign scholars. By the cutting experiment and simulation of cutting iron-based superalloy with coated carbide tools [7], cutting the nickel-based superalloy with the PCBN tools [8], cutting the nickel-based superalloy in high-speed with the PCBN tools [9], the research, for the high temperature alloy cutting performance influenced by such factors as rake angle, tip radius, negative chamfer parameters and PCBN material and so on was conducted. In the paper, based on the result of the single factor experiment for the tool material, the single factor experiment, in which, the rake angle and tip radius were as single factor various, was conducted. The cutting force obtained from the experiment was analyzed and the influence of turning high temperature alloy GH4169 produced by the tools geometry parameters. In the single factor experiment, in which the tool geometry parameters were as single factors, the correctness of simulation modal established by ABAQUS software was verified, and meanwhile, the influence of cutting force produced by rake angle and tip radius was researched, all of which provide the technical support for the machining of GH4169.

\section{The Establishment of Simulation Modal}

The essential work, such as the arrangement of seeds grid of high temperature alloy GH4169, element shape set, element type set, meshing techniques and algorithms set, meshing and mesh quality inspection and so on, was finished with the Mesh functional module in ABAQUS/CAE. The two-dimensional orthogonal cutting model after meshing was shown in Figure 1.The grid in the cutting zone was meshed intensively, but the grid far from the cutting zone was thin gradually. The element type of grid after meshing is four node plane strain reduced integral unit CPE4RT.

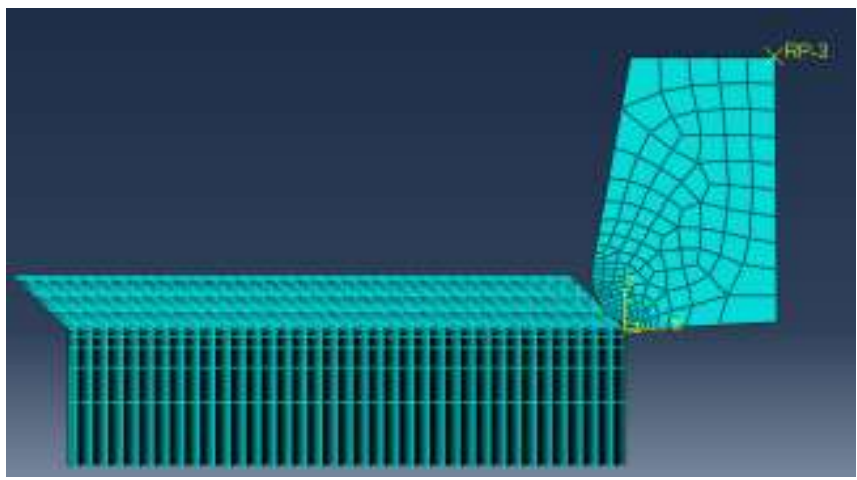

Figure 1. Two-Dimensional Orthogonal Cutting Grid Model

\section{The Design for Experiment}

\subsection{The Establishment of Experimental System}

The established experimental system consist of four parts: the machining equipment is Ordinary horizontal lathe CA6140; The work-piece size is Bar with $\Phi 155 \times 60$; The material of the tools is Coated Carbide KC5510; The dynamometer 9257B measuring force system made in the Kistler, which is shown in Figure 2. 


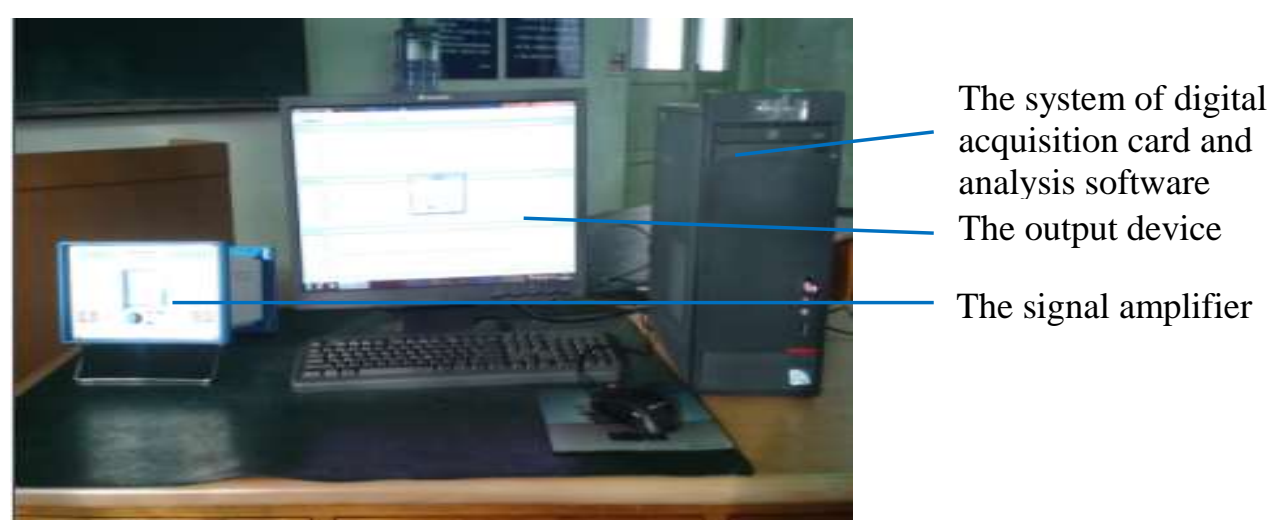

Figure 2. The Measurement System of Cutting Force

\subsection{The Simulation and Experiment Condition}

The cutting amount: cutting speed: $v_{c}=50 \mathrm{~m} / \mathrm{min}$. The feed rate: $f=0.15 \mathrm{~mm} / \mathrm{r}$, The back cutting depth: $a_{p}=0.4 \mathrm{~mm}$; The tools geometry parameter: The tool relief angle: $\alpha=3^{\circ}$.

\section{The Research for the Experiment and Simulation of Cutting Force}

\subsection{The Influence of Cutting Force caused by Rake Angle}

In the experimental condition mentioned above, the regular pattern of cutting force was studied when the rake angle respectively is $3^{\circ}, 7^{\circ}, 10^{\circ}, 12^{\circ}$. The changing curve of cutting force influenced by the change of rake angle was shown in Figure 3, was obtained after processing experimental data by extracting the average value of cutting force in each direction. When the cutting process is in the steady state, the comparison of the back force $\boldsymbol{F}_{\boldsymbol{y}}$ obtained from experiment and simulation, and was shown in Figure 4. The compared curve of cutting force was shown in Figure 5.

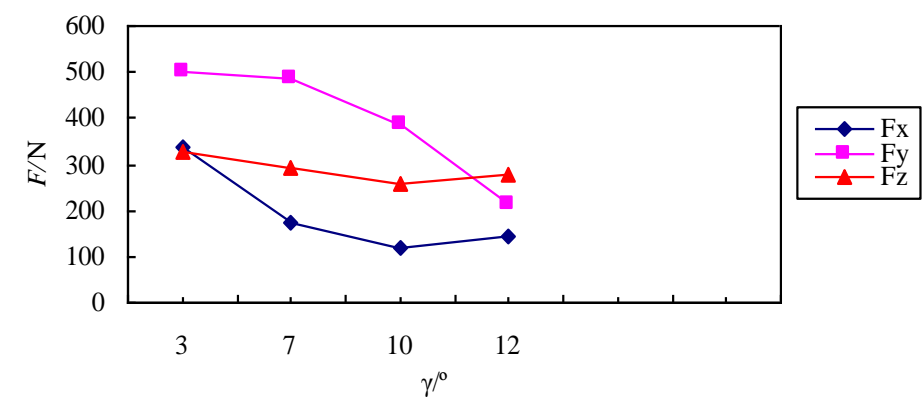

Figure 3. Cutting Force is Affected by Cutting Tool Rake Angle

As the Figure 3, shown that: with the rake angle increasing, the feed force $\boldsymbol{F}_{\boldsymbol{x}}$ and the main cutting force $\boldsymbol{F}_{z}$ performed decreasing slowly, when the rake angle increase to $10^{\circ}$, the feed force $\boldsymbol{F}_{x}$ and the main cutting force $\boldsymbol{F}_{z}$ decrease to the minimum value. Being the rake angle $10^{\circ}$ as the inflection point, the feed force $\boldsymbol{F}_{\boldsymbol{x}}$ and the main cutting force $\boldsymbol{F}_{z}$ would perform the increasing trend slowly.

The back force $\boldsymbol{F}_{\boldsymbol{y}}$ will increase to $502 \mathrm{~N}$ when the rake angle is $3^{\circ}$. When the rake angle increase to $7^{\circ}$, the back force $\boldsymbol{F}_{\boldsymbol{y}}$ decreased to $486 \mathrm{~N}$. With the rake angle increasing to $10^{\circ}$, the back force $\boldsymbol{F}_{\boldsymbol{y}}$ decreased to $423 \mathrm{~N}$. When the rake angle increased to $12^{\circ}$, the back force continuously decreased to $254 \mathrm{~N}$. By comprehensively analyzing, the preferred rake angle is $10^{\circ}$. 


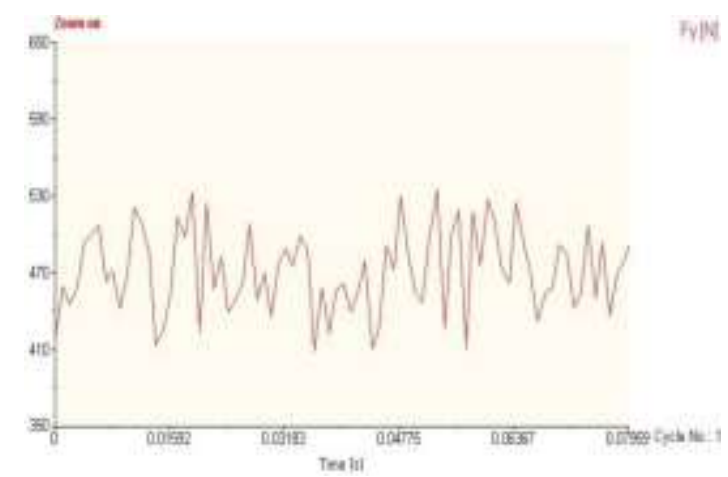

a) the dynamic cutting force changing curve obtained from experiment

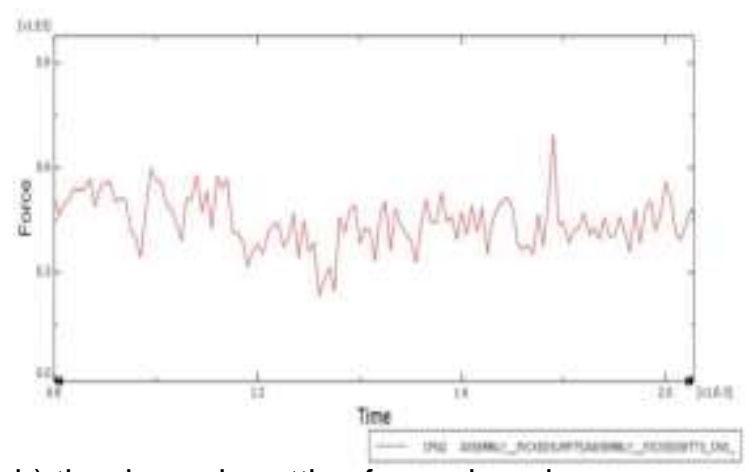

b) the dynamic cutting force changing curve obtained from simulation

Figure 4. The Changing Curve of Cutting Force when $y=3^{\circ}$

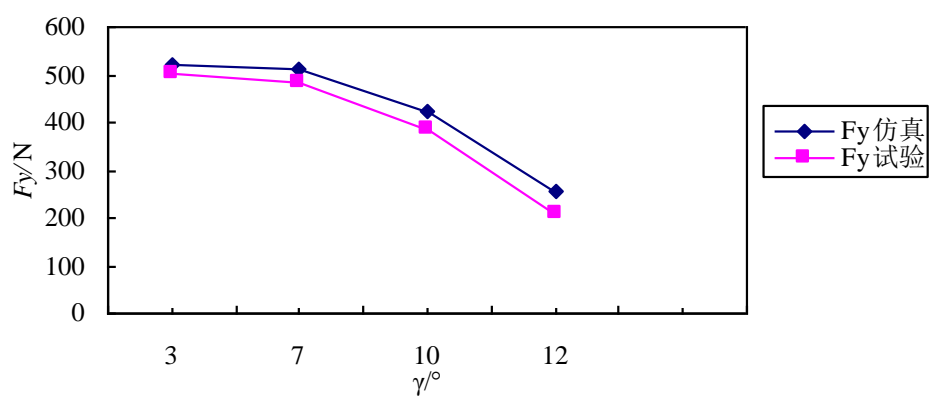

\section{Figure 5. Comparison of Simulation and Experiment of Cutting Force}

From the Figure 5, we can see that: the changing trend obtained from simulation and experiment are consistent. Because the blunt edge radius will decrease gradually when the rake angle gradually increased, which will directly lead to the strengthening of cutting action in the edge of tool and the decreasing of produced cutting force. Meanwhile, the shear angle in the cutting process will increase with the rake angle increasing, which also lead to the decrease of cutting force.

\subsection{The Influence of Cutting Force Caused by Tools Tip Radius}

In the experimental condition mentioned in the second part, the regular pattern of cutting force was studied when the tip radius respectively is $0.2 \mathrm{~mm}, 0.4 \mathrm{~mm}, 0.8 \mathrm{~mm}$ and $1.2 \mathrm{~mm}$. The changing curve of cutting force influenced by the change of tip radius, shown as figure 6 , was obtained after processing experimental data by extracting the average value of cutting force in each direction. When the cutting process is in the steady state, the changing curve of the back force $\boldsymbol{F}_{\boldsymbol{y}}$ obtained from experiment and simulation, were respectively shown in Figure 7. The compared curve of cutting force was shown in Figure 8.

As the Figure 6, shown that: in the process of the tip radius increasing from $0.2 \mathrm{~mm}$ to $0.4 \mathrm{~mm}$, the feed force $\boldsymbol{F}_{\boldsymbol{x}}$ and the main cutting force $\boldsymbol{F}_{z}$ increase slowly, but the back force $\boldsymbol{F}_{\boldsymbol{y}}$ has little change. When the tip radius increases from $0.4 \mathrm{~mm}$ to $1.2 \mathrm{~mm}$, the feed force $\boldsymbol{F}_{\boldsymbol{x}}$ and the main cutting force $\boldsymbol{F}_{\boldsymbol{z}}$ almost have little change, but the back force $\boldsymbol{F}_{\boldsymbol{y}}$ increases gradually. So the optimized tip radius is $0.4 \mathrm{~mm}$. 


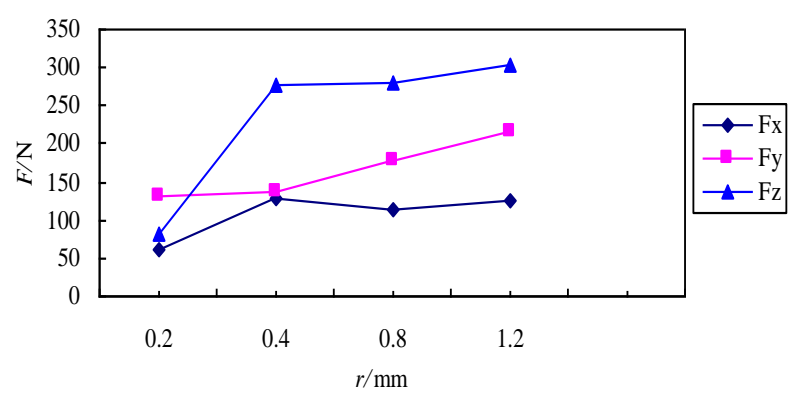

Figure 6. Influence of Tip Radius on Cutting Force
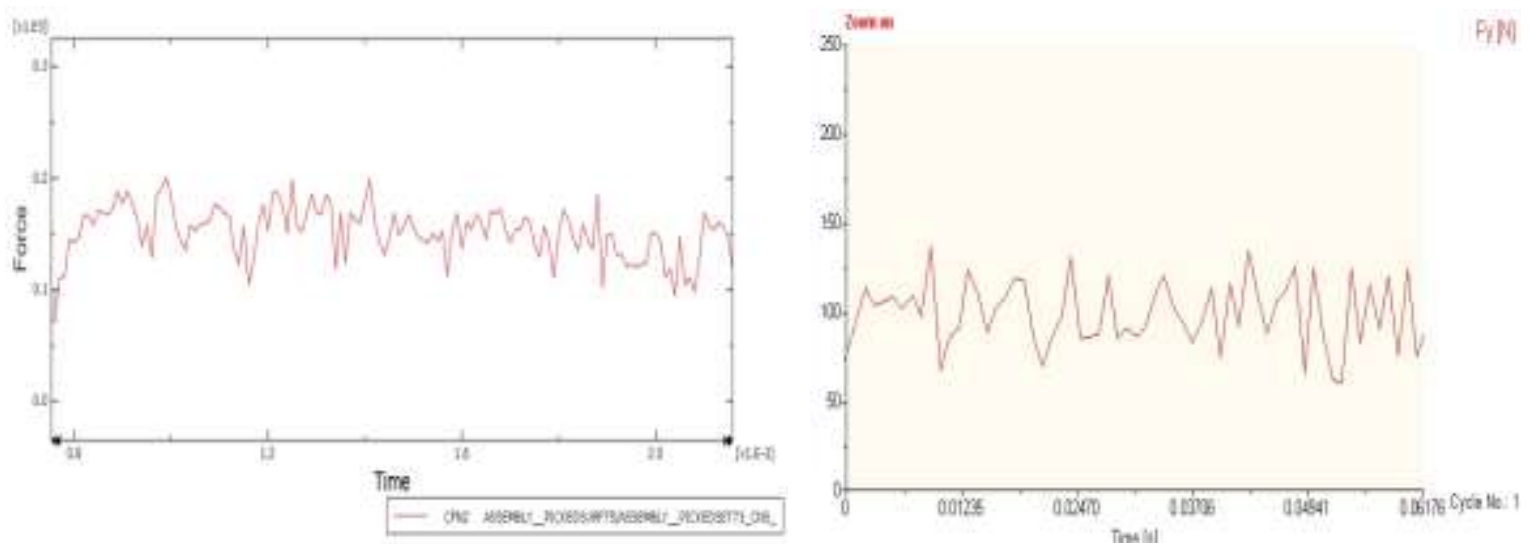

a) the dynamic cutting force changing curve obtained from experiment

b) the dynamic cutting force changing

Figure 7. The Changing Curve of Cutting Force when $r=0.2 \mathrm{~mm}$

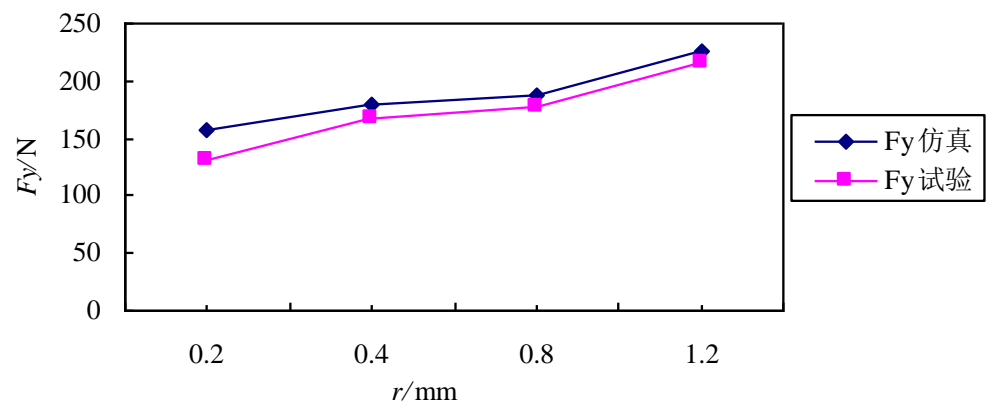

Figure 8. Comparison of Simulation and Experiment of Cutting Force

From the Figure 8, we can see that: the changing trend obtained from simulation and experiment are consistent. With the tip radius increasing, the cutting force is increasing. Because the blunt edge radius will increase gradually, in the process of tip radius increasing gradually, which will directly lead to the weakening of cutting action in the edge of tool and the increasing of cutting force. However, in the process of tip radius decreasing gradually, the tip more sharp, the easier to cutting, which lead to the appearance of smaller cutting force. Always, the tip wear is very serious. 


\section{Conclusion}

In this paper, the influence of cutting force produced by rake angle and the tip radius was researched. From the study, we can conclude that with the rake angle increasing, the back force $\boldsymbol{F}_{\boldsymbol{y}}$ decreased gradually but the feed force $\boldsymbol{F}_{\boldsymbol{f}}$ and the main cutting force $\boldsymbol{F}_{z}$ increased slowly after the rake angle reflection angle $10^{\circ}$; With the tip radius increasing gradually, the back force increases gradually.

By the simulation of the finite element analysis software ABAQUS, the law that the cutting force was changed with the changing of rake angle and tip radius was obtained. Meanwhile, by the comparison of the result obtained from experiment and simulation, we could find that the changing trend between them was consistent.

From the research above, the conclusion could be obtained: the rake angle suitable for cutting the high temperature alloy is $10^{\circ}$ and the tip radius is $0.4 \mathrm{~mm}$.

\section{Acknowledgements}

This work was supported by Heilongjiang Provincial Education Department Project "Thin-walled high-speed milling technology research and multi-objective optimization" (12541691) and Heilongjiang Province Natural Science Foundation "Superalloy thinwalled high-speed milling stability and optimization of process parameters"(E201328).

\section{References}

[1] Z. Zhuang, F. Zhang and S. Cen, "Abaqus non-linear finite element analysis and examples, Beijing Science Press, (2005).

[2] X. Zhu, "The Research and Analysis on Influence of Roughness Produced by High-Speed Cutting Parameters", Mechanical \& Electrical Engineering Technology, vol. 11, no. 39, (2010).

[3] X. Teng, T. Wierzbicli and H. Couque, "On the transition from adiabatic shear banding to fracture", Mechanics of Materials, vol. 39, (2007).

[4] C. Yuan, "Finite Element Simulation and Analysis for High-speed Machining High temperature alloy GH4169”, Qingdao Technological University, (2011).

[5] X. Wu and Y. C. Zhaolei, "Study on Surface Roughness in Turning GH4169 Superalloy by Using Ceramic Tool”, Aeronautical Manufacturing Technology, vol. 19, (2012).

[6] M. Tianyu, Y. WANG and Y. F. L. Yu-Fu, "Research on Cutting High Temperature Alloy by Ceramics Tool", Aviation Precision Manufacturing Technology, vol. 48, (2012).

[7] Z. Feng, "Research on Cutting the Iron-based Superalloy with the Coate Carbide Tools", Dalian University of Technolog, Dalian university of Technology, (2013).

[8] S. Tingke, L. Man and Z. Hongtao, "Research on the cutting property of polycrystalline carbide boron (PCBN) tools in turning nickel-based superalloy GH4169", Diamond \& Abrasives Engineering, vol. 1, no. 38, (2011).

[9] C. Li, "Experimental and Simulation Research on High Speed Turning Nickel-based Superalloy with PCBN Cutting Tools”, Xiangtan University, (2014). 